\title{
ESTUDO SOBRE NOMENCLATURA NA NAVEGAÇÃO DE PORTAIS UNIVERSITÁRIOS BRASILEIROS
}

\author{
Elton R. Vieira \\ Universidade Federal de Pernambuco \\ (eltonrvs@gmail.com)
}

\begin{abstract}
Resumo: Portais universitários são uma das ferramentas mais importantes para a comunicação entre as instituições e o público. Devido ao grande volume de informação, tais ambientes virtuais devem carregar características de boa usabilidade e navegabilidade. Dos princípios, teorias e heurísticas que regem a usabilidade, consistência e convenções são apreciadas como importantes na construção de um sistema fácil de utilizar. Este trabalho buscou estudar consistência e convenção, focado na nomenclatura e posicionamento dos links de menus da navegação principal, secundária e local dos portais universitários. Foi desenvolvido um framework, através de uma análise quantitativa dos resultados obtidos, contendo informações sobre os rótulos e posicionamento mais utilizados pelas universidades em seus ambientes web. Dessa forma, o framework passa a ser um guia de referência no desenvolvimento e/ou redesign desses portais de comunicação.
\end{abstract}

Palavras-chave: Portais Universitários, nomenclatura, consistência, convenção, framework.

Abstract: Universities home page are fundamental tools for institutionpublic comunication. Due to the large volume of informations, such virtual environments must carry some good usability and navegation features. There are theories, principles and heuristics governing the usability, and consistency e convention are appreciated as important in the development of a good to use system. These work studies consistency e convention, focused on naming and positioning of menu links in primary, secundaty and local navigations of the universities home page. It was developed a framework, by quantitative analyses of th results obtained, with informations about the nomenclature and positioning more used by universities in their virtual environment. Thus, the framework became a reference guide in the development and/or redesign of these communication portals. 
Palavras-chave: Universities Home Pages, naming, consistency, convention, framework.

\section{INTRODUÇÃO}

O ensino superior no Brasil está crescendo ano após ano. As últimas pesquisas divulgadas pelo Ministério da Educação (2013) afirma que existem mais de 7 milhões de pessoas matriculadas em cursos de graduação públicas e privadas. As instituições de ensino têm em seus sites/portais a grande responsabilidade de gerar informação para os públicos internos e externos. Desse modo, estudar a facilidade de uso dos sites/portais passa a ter real importância na interação universidade-estudantesociedade.

Os sites/portais universitários necessitam moldar-se às expectativas do usuário, em um cenário onde o seu perfil não é facilmente definido e as possibilidades de acesso à internet só aumentam. Há autores (LOSADA DIAZ, 2002; CORNELLA, 2003) que afirma que as universidades ainda não chegaram a adaptar seu conteúdo e interface ao novo contexto fornecido pela sociedade da informação.

Diversos autores estudam as melhores práticas na construção de um ambiente virtual para a internet (Nielsen, 2000; Norman, 2006; Krug, 2008; Agner 2006; Padovani e Moura, 2008; Bastien e Scapin, 1993; Bach e Scapin, 2003). Pesquisam temas como navegação, interação homem-máquina, usabilidade e design de interação. Todos esses assuntos evocam conhecimentos sobre como tornar o ambiente web mais fácil para o usuário.

Entre centenas de conceitos sobre como desenvolver um site ideal, Nielsen e Loranger (2007), Norman (2006) e Memória (2005) afirmam que termos e nomenclaturas utilizadas no ambiente web devem ser compatíveis com o mundo real e ter padrões consistentes e claros. Tal conceito não é suficiente para tornar um site fácil de utilizar, mas é essencial para quem o assim deseja.

O trabalho ora apresentado busca estudar 50 sites/portais universitários e averiguar se o comportamento dos links utilizados nos menus de navegação principal, secundária e local, apresenta consistência (Nielsen, 2005; Norman, 2006) e/ou obedece a convenções (KRUG, 2008; NIELSEN e LORANGE, 2007), quando relacionadas à suas nomenclaturas e posicionamentos. Em um segundo momento, desenvolver um framework contendo os rótulos e os locais mais frequentes utilizados na navegação dos ambientes virtuais estudados.

O trabalho está dividido em mais três seções, cada uma dela contribuindo para a narrativa da pesquisa: Desenvolvimento, nessa seção será exposto o referencial teórico utilizado na construção do artigo, assim como a metodologia utilizada na pesquisa; na seção Resultados apresentamos os dados e informações coletados a partir da metodologia de pesquisa e o framework desenvolvido a partir das informações levantadas; por fim, a seção de Conclusão. 


\section{DESENVOLVIMENTO}

A estrutura e conteúdo de um website são elementos importantes, mas não suficientes para torna-la fácil de utilizar. É o design de interface que vai fazer com que o ambiente virtual seja visualmente interessante e agradável para se navegar. A partir desse ponto, veremos os conceitos, temas e metodologia que permearam esta pesquisa.

\subsection{Referencial Teórico}

Preece et al (2013) define design de interação como o design de produtos interativos que auxiliam as pessoas na maneiro como trabalham, se comunicam e interagem. Está relacionada com áreas como Ergonomia, Ciências da Computação, Psicologia, Interação Homem-Máquina, Design, etc. O processo de design de interação envolve, basicamente, quatro atividades: identificação de necessidades e requisitos, desenvolvimento de alternativas, construção de versão interativas e avaliação.

Todas essas atividades são importantes para o desenvolvimento de um bom ambiente virtual, contudo, os aspectos do design de interação de maior interesse para os web designers são o design de navegação e usabilidade do sistema (WILLIAMS, 2001). Para alcançar a excelência nessas duas características, pesquisadores da área desenvolveram alguns princípios de usabilidade e heurísticas para serem aplicados a um ambiente virtual (Nielsen, 2005; Norman, 2006; Krug, 2008; Agner, 2006).

Primeiramente, é necessário entender o que são princípios e heurísticas quando aplicado a esse contexto. Princípios de usabilidade são recomendações para o desenvolvimento do ambiente virtual, heurísticas são quando os princípios são utilizados para auxiliar na avaliação desses ambientes (PREECE, 2005).

Prevenção de erros, consistência, feedback, controle do usuário, carga cognitiva e consistência são alguns dos princípios defendidos por pesquisadores na área como imprescindíveis para uma boa usabilidade do ambiente virtual. Agner (2006) elege consistência como o primeiro princípio a ser estudado das famosas "Regras de Ouro" de Shneiderman (2010), presente em todas as listas de princípios dos autores supracitados.

Segundo Shneiderman op cit, consistência é a repetição de padrões no ambiente virtual, ou seja, elementos que tenham funções parecidas devem funcionar de formas semelhantes, assim como sua aparência e nomenclatura. A não aplicação desse princípio pode levar confusão ao usuário, fazendo-o cometer erros e frustrando a experiência da navegação. Nielsen e Lorange (2007) diz que os ambientes virtuais devem falar a mesma língua o tempo todo, nunca identificando a mesma ação com palavras diferentes.

A consistência não deve ser analisada apenas internamente, mas deve ser explorada para que os usuários sintam-se confortáveis a utilizar o ambiente virtual baseada em suas experiências em outros ambientes. Krug (2008) afirma que as convenções de nomenclatura e posicionamento dos elementos de ambientes web ajudam o usuário a navegar no sistema sem que haja grande carga cognitiva.

Quando aplicamos esses conceitos em portais/sites universitários, tornam-se ainda mais importantes, devido ao grande volume de conteúdo e serviços que esses ambientes possuem. Santamaria e Monteiro (2013) apontam a importância dos portais/sites de universidades como um elo entre a população, estudantes e a instituição. Esse trabalho visa entender como elementos de navegação se comportam 
nesses ambientes, auxiliando na construção de sistemas que respondam às necessidades e demandas de usabilidade.

\subsection{Metodologia}

O princípio da consistência é defendido como uma das propriedades mais importantes de um ambiente virtual (Nielsen, 2007, Norman, 2006). Memória (2006) afirma a importância em obedecer à consistência no desenvolvimento de sites e apontou a inexistência de um estudo sobre o tema para a internet brasileira, principalmente tratando-se de estudos de nomenclatura utilizados nesses ambientes virtuais.

Oportunamente, esta lacuna de pesquisa foi escolhida como foco de estudo. Porém, graças à infinidade de temas e objetivos dos sites/portais na internet foi necessário reduzir e definir o universo de pesquisa. Partindo das informações discutidas na introdução deste trabalho, estabeleceu-se que seriam estudados os portais/sites de universidades. Ou seja, o crescimento da oferta de cursos de graduação no país, a complexidade e a grande carga de informação disponibilizada aos seus usuários serviram de motivação para a escolha. Ainda foi definido que a pesquisa estudaria os termos e nomenclatura utilizada nas navegações primária, secundária e local da página inicial dos portais (KRUG, 2008). Novamente, o recorte foi imperativo para o desenvolvimento da pesquisa, pois esses ambientes apresentam alto nível de profundidade, muitas vezes, mudando completamente o teor do conteúdo informacional nas páginas internas.

Esta pesquisa apresenta-se primordialmente como quantitativa, pois se caracteriza pelo emprego da quantificação, tanto nas modalidades de coleta de informação, quanto no tratamento dessas através de técnicas estatísticas, desde as mais simples até as mais complexas (RICHARDSON, 1989). O framework, um dos objetivos principais deste trabalho, é construído a partir do total de frequência e local que determinados termos aparecem nos portais pesquisados.

Como meio de escolher quais instituições teriam seus portais/sites pesquisados, foi utilizado o "RUF - Ranking Universitário Folha", da Folha de São Paulo. O RUF utiliza metodologia baseada nos rankings internacionais, como o Times Higher Education e Quacquarelli Symonds. O ranking classificou 232 instituições de ensino do Brasil, sendo 41 faculdades e 191 universidades. Para essa pesquisa, foram pesquisadas as 50 primeiras posições do Ranking Universitário Folha 2013.

\subsection{Resultados Obtidos}

No quadro 1 estão indicadas todas as instituições que tiveram seus portais/sites analisados. Como resultado do RUF, a lista é formada por 43 universidades públicas e 7 universidades privadas. 
Quadro 1 - 50 primeiras posições do RUF - Ranking Universitário Folha 2013

\begin{tabular}{|l|l|l|l|l|}
\hline USP & UFMG & UFRJ & UFRGS & UNICAMP \\
\hline UNESP & URPR & UNB & UFSC & UFPE \\
\hline UERJ & UFBA & PUC-RIO & UNIFESP & UFF \\
\hline PUC-RS & UFSCAR & UFC & UEM & UFSM \\
\hline UFRN & UFV & UFG & UFPA & UEL \\
\hline UFPB & PUC-PR & UFU & UFPEL & UFLA \\
\hline Mackenzie & UFES & UFMS & UNISINOS & UFAL \\
\hline UFOP & UFJF & UENF & PUC-MINAS & UFMT \\
\hline PUC-SP & UFRRJ & UFCG & UECE & UNIOESTE \\
\hline UEPG & UFTM & UFCSPA & UNIFEI & UEFS \\
\hline
\end{tabular}

Fonte: Ranking Universitário Folha. Acessado em: 25 de fevereiro de 2014.

Durante o estudo, provou-se a premissa desta pesquisa: a nomenclatura e o local dos links de Menu utilizadas nos portais universitários variavam, ainda que a função seja a mesma. Por exemplo, foram utilizados os termos "Intercâmbio" e "Internacional" com mesmo objetivo, de levar a páginas com mais informações sobre programas de intercâmbio. Assim, foi estabelecido que as funções dos links que teriam suas nomenclaturas avaliadas deveriam ocorrer, no mínimo, em 20 portais diferentes pertencentes às amostras estudadas. Como resultado, chegou-se às funções apresentadas no quadro 2 .

\section{Quadro 2 - Funções de links que ocorrem em pelo menos 20 portais universitários}

\begin{tabular}{|l|l|l|l|l|l|}
\hline Ensino & Pesquisa & Extensão & Graduação & Pós-Graduação & Concursos \\
\hline Institucional & Administração & Notícias & Ouvidoria & Intercambio & Serviços \\
\hline
\end{tabular}
Fonte: Elaborado pelo autor, com base na pesquisa realizada.

A primeira função estudada foi Ensino. Tal link é utilizado no menu para caracterizar principalmente as modalidades de graduação, pós-graduação, especialização, ensino técnico e links referentes a eles. O rótulo "Ensino" ocorre 21 vezes nos 50 portais estudados. Diferentes termos que foram utilizados na mesma função foram "Estudante"/"Estude na [Universidade]" (5 ocorrências), "Acadêmico" (4 ocorrências) e Cursos (5 ocorrências). O termo "Ensino" é raramente visto em outro lugar que não seja no Menu de Navegação Principal, aparecendo em 19 oportunidades.

O link Pesquisa é utilizado nos Menus dos portais acadêmicos para links que façam referências aos projetos de pós-graduação da instituição, sejam relacionados aos cursos e linhas de pesquisa existentes, sejam relacionadas a informações institucionais (Secretarias de Pós-Graduação, Editais de Bolsas, laboratórios, etc.). 0 termo "Pesquisa" aparece como o rótulo mais utilizado nos portais , com 28 aparições. Seguidas de "Pesquisa e Inovação" e "Pesquisa e Pós-graduação", com cinco e seis ocorrências respectivamente. O termo "Pesquisa" está presente predominantemente na navegação global, com 21 ocorrências.

O rótulo "Extensão" se fez presente em 35 dos portais acadêmicos pesquisados. $O$ termo foi utilizado para links relacionados aos projetos de extensão das instituições. Ocorreu predominantemente na navegação global, com 26 ocorrências. 
Outros termos utilizados para o mesmo fim foram "Extensão e Cultura" (3 ocorrências) e "Cursos de Extensão" (1 ocorrência).

Essas três funções representam a máxima defendida pelas universidades, logo apareceram juntas na navegação principal em 19 oportunidades utilizando os termos de maior frequência.

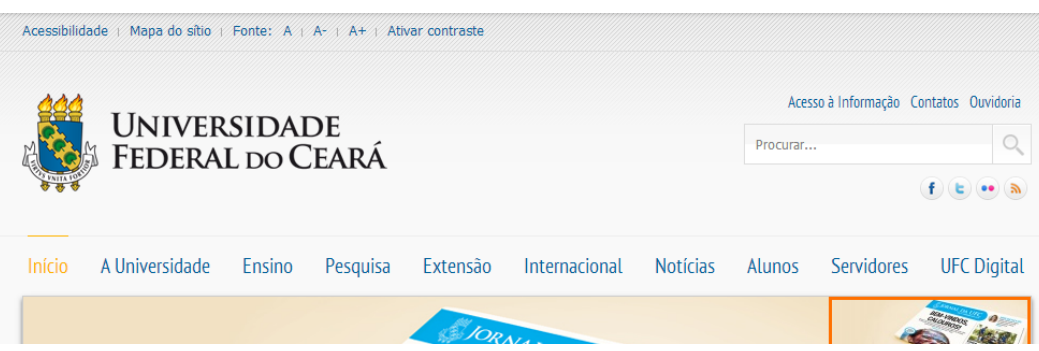

Figura 1 - Portal da Universidade Federal do Ceará com os termos "Ensino", "Pesquisa" e "Extensão" na navegação principal.

Em alguns casos, os termos "Ensino" e "Pesquisa" eram substituídos pelos termos "Graduação" e "Pós-Graduação" na navegação principal. Quando isso ocorria, os rótulos "Ensino" e "Pesquisa" assumia outra função, que não as supracitadas, fazendo-os serem descartados dos resultados. Contudo, na maioria dos portais, os termos "Graduação" e "Pós-Graduação" apareciam como subseção do rótulo "Ensino": "Graduação" apareceu 15 vezes na Navegação principal e 20 vezes como navegação secundária; "Pós-Graduação" apareceu 13 na navegação principal e 17 vezes como secundária. Só em cinco ocasiões, o termo "Pós-graduação" foi substituído por "Mestrado e Doutorado". Os rótulos mais utilizados para informações relativos aos programas de ensino da instituição são: "Ensino", "Pesquisa" e "Extensão", com "Graduação" e "Pós-Graduação" como subseção de "Ensino".

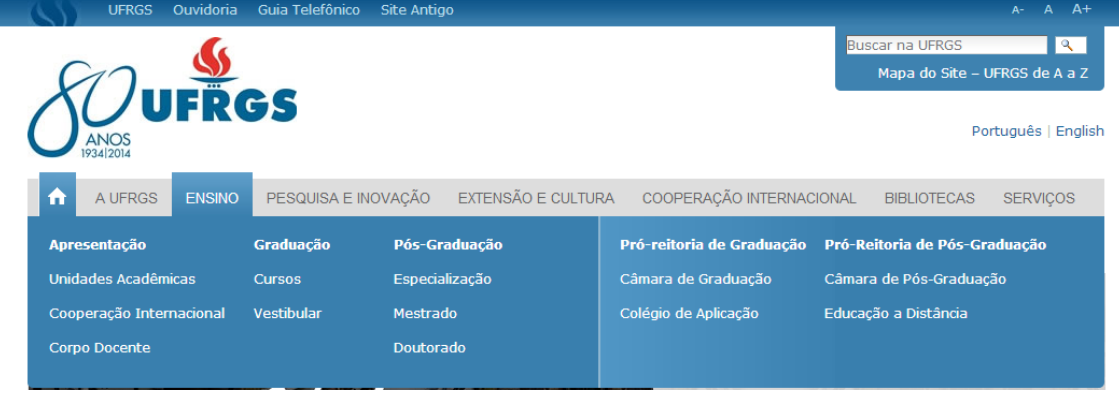

Figura 2 - Portal da Universidade Federal do Rio Grande do Sul com os termos "Graduação" e "Pós-Graduação" na navegação secundária do rótulo "Ensino" da navegação principal.

Para informações relativas às instituições, dois termos aparecem com bastante relevância: "Institucional" e "A [Universidade]". Os dois termos tem nível de formalidades diferentes. "Institucional", termo mais formal, ocorre em 18 portais, predominantemente na navegação principal (12 ocorrências). "A [Universidade]", termo menos informal, aparece em 17 oportunidades, e seguindo ao rótulo anterior, ocorre principalmente na navegação principal, com 15 aparições. Outros termos que são utilizadas para a mesma função são: "Conheça a [Universidade]" (4 ocorrências), 
"Sobre a [Universidade]" (3 ocorrências), "Estrutura da Universidade" (1 ocorrência). Esses últimos aparecendo na navegação principal da página inicial dos portais.

Alguns portais estudados trazem em sua página principal links que levam a informações sobre a administração da instituição, como equipe de gestão, próreitorias, licitações e etc. Para essa função, termo "Administração" foi utilizado em 17 oportunidades, predominantemente na navegação principal da página inicial. Apesar da clareza do termo, ainda foram utilizados para o mesmo fim, rótulos como "Administração Central" ( 2 oportunidades) e "Estrutura ADM" (uma oportunidade). Há casos onde o termo aparece na navegação das subseções e navegação local referindose ao curso de Administração, nesse caso a contagem foi desconsiderada.

Trinta e seis dos portais pesquisados carregam em suas ferramentas, presentes na página inicial, um espaço reservado àqueles que querem entrar em contato com a instituição. Para esse fim, os rótulos mais utilizados foram "Fale Conosco" e "Ouvidoria". O termo "Ouvidoria" foi utilizado em 28 oportunidades, em detrimento de "Fale Conosco" que apareceu em apenas 13 portais. Os dois links estavam localizados com maior frequência na navegação local.
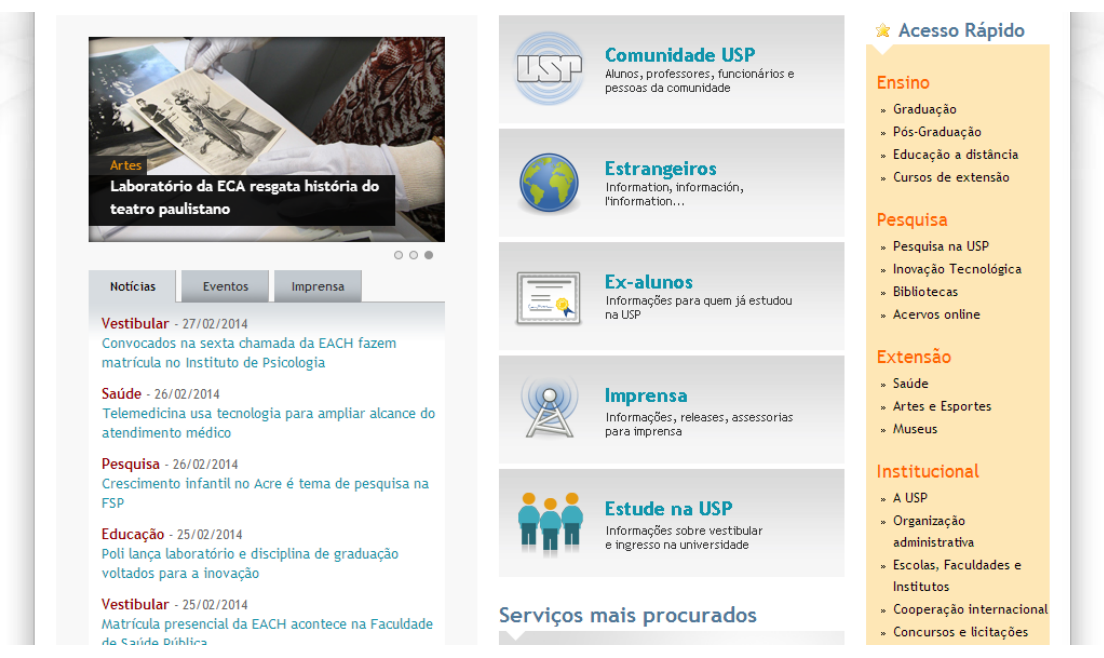

\section{Figura 3 - Portal da Universidade de São Paulo utilizando a nomenclatura mais comum aos links.}

As universidades pesquisadas prezam suas relações com instituições de fora do país. A maioria dos portais têm em sua página principal links que levem a informações sobre programas de intercâmbio. Com esse objetivo foram utilizados os seguintes rótulos: Cooperação Internacional (5 vezes), Internacional (8 vezes), Internacionalização (1 vez), Intercâmbio [Internacional] (5 vezes) e Relações Internacionais (13 vezes). Excetuando "Internacionalização", os outros termos aparecem predominantemente na navegação secundária, geralmente do termo "Institucional" (6 casos) e "Administração" (4 casos).

Outro modo de coletar informações sobre a instituição de ensino é através do mural de notícias. $O$ estudo da navegação apontou que 34 portais possuem links que levam a esses murais. Os termos mais utilizados foram: Boletim/Jornal (13 vezes), Notícias (12 vezes), Imprensa/Sala de Imprensa (9 vezes).

Dos portais pesquisados, $86 \%$ pertencem a instituições públicas. Nesse caso, 0 único modo de ingresso profissional é por meio de concursos e editais. Apesar dos 
termos, no contexto estudado, significarem geralmente a mesma coisa, houve discrepância entre as utilizações dos mesmos. "Concursos"/"Concursos Públicos" apareceu 22 vezes, ao passo que "Editais" apenas em 13 oportunidades. Seria compreensível a utilização dos dois termos juntos como modo de reforçar suas funções, porém o termo "Concursos e Editais" apareceu apenas em seis ocasiões.

Por fim, entre os termos que mais se ocorreram está a função de serviços. Que podem ser apenas serviços internos da instituição, como serviços abertos à comunidade. Eram utilizados os mesmos rótulos para essas funções. No caso, predominantemente o termo "Serviços" (30 vezes) ocorreu na navegação global dos portais. "Serviços à comunidade" e "Atendimento à comunidade" ocorreram três vezes.

\subsection{Construção do Framework}

Os resultados adquiridos demonstram uma não-uniformidade na nomenclatura adotada pelos principais websites acadêmicos do Brasil. Mesmo que haja termos constantemente utilizados, devido a própria estrutura física das instituições, a estrutura digital de seus portais obedecem apenas nas necessidades internas e regimentos das Universidades.

Essa heterogeneidade de soluções de interface pode acarretar transtornos para quem necessita utilizar serviços de mais de um portal acadêmico. Para a melhor utilização dos portais acadêmicos pela população, seria necessário trabalhar a homogeneização da interface desses ambientes. Tornando, assim, a navegação dos portais acadêmicos mais reconhecíveis por qualquer usuário, de qualquer instituição de ensino.

Framework é uma solução originária da Ciência da Computação, e segundo FAYAD et al (2006) consiste em um esqueleto de uma aplicação que pode ser customizado de acordo com a necessidade do projeto. Para essa pesquisa, adotaremos o framework como a captura de funcionalidades comuns a várias aplicações de software. Essas aplicações devem pertencer a um mesmo domínio de problema (APPLETON, 2014).

Utilizando-se das informações levantadas após a análise dos dados de pesquisa e apoiado na estrutura gráfica e arquitetônica dos wireframes (Memória, 2005), foi construído o seguinte framework:

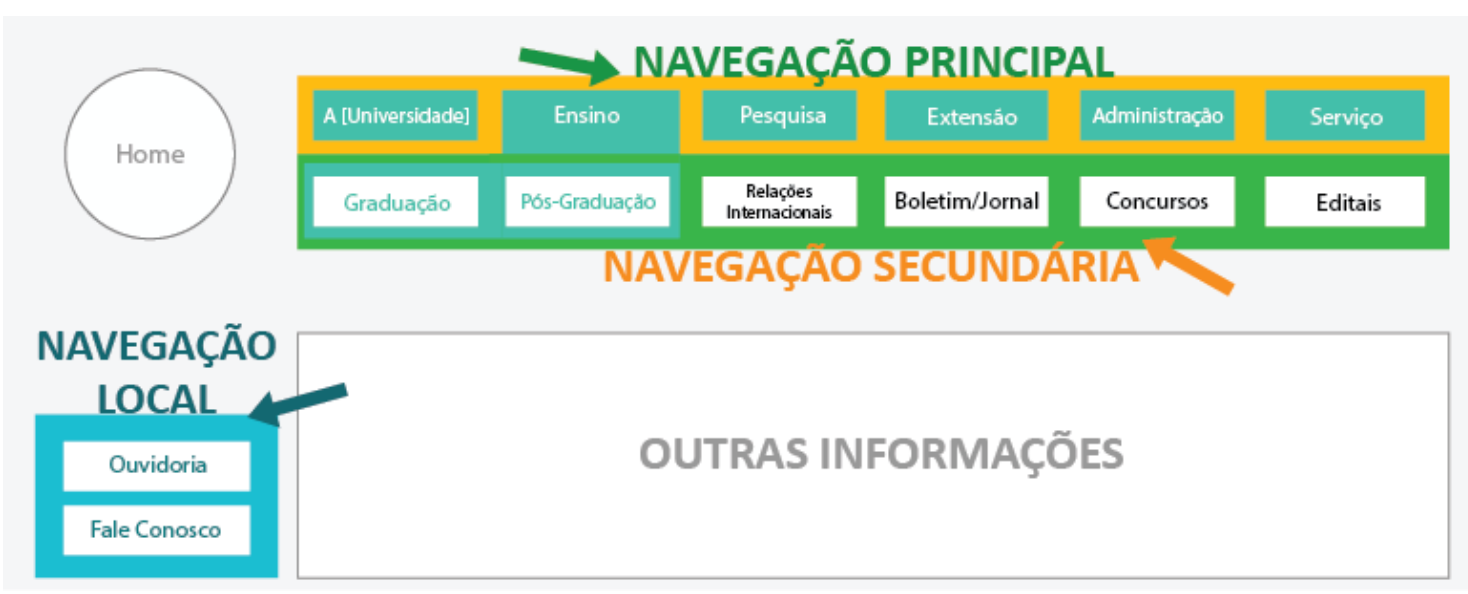




\section{Figura 4 - Framework de apresentação da nomenclatura e posicionamentos mais utilizados pelos portais universitários pesquisados.}

A construção do framework (Figura 4) mostra que a navegação principal de um portal universitário tende a apresentar os rótulos "A [Universidade]", "Ensino", "Pesquisa", "Extensão", "Administração" e "Serviço". Na navegação secundária estão "Graduação" e "Pós-Graduação", vinculadas à "Ensino", "Relações internacionais", "Boletim/Jornal", "Concursos" e "Editais", esses últimos, geralmente fazendo parte hierarquicamente das funções "A [Universidade]" e/ou "Administração". "Ouvidoria" e "Fale Conosco" ficam fixos na navegação local. A nomenclatura utilizada e posicionamento dos links podem ser tratados como convenções na construção de um portal universitário. Porém, é preciso lembrar que o contexto é importante na construção desses ambientes. A instituição pode ter a necessidade de colocar mais informações na navegação, como de fato ocorre na maioria dos portais pesquisados.

O framework desenvolvido como resultado dessa pesquisa tem que ser tratado como um guia de convenções, e não como imposição na construção de portais universitários. Contudo, seguir convenções é um excelente modo de conseguir consistência no ambiente web, facilitando a sua navegação e utilização (Krug, 2008).

\section{CONCLUSÕES}

\subsection{Conclusões}

Ao final do estudo, é possível afirmar que os objetivos foram alcançados. A partir dos 50 portais universitários estudados, e respeitando a heterogeneidade dos ambientes virtuais, foi possível evidenciar a nomenclatura mais utilizada para guiar a navegação nas páginas iniciais. Ficou claro que mesmo apresentando função semelhante, em várias situações, links de menus possuíam rótulos diferentes e posicionamento diferentes. Ação que vai de encontro aos conceitos de consistência e convenção defendidos por Norman (2006), Nielsen (2010) e Krug (2008).

Este trabalho também evoca a importância do estudo de princípios e heurísticas de desenvolvimento de ambientes web. Tais elementos podem e devem ser aplicados na construção da navegação (Padovani e Moura, 2008). Esse estudo foca na navegação principal, secundária e local da página inicial dos portais universitários, mas o princípio nativo dessa pesquisa pode ser aplicado às outras páginas no ambiente virtual.

Durante o levantamento bibliográfico, nenhum trabalho foi encontrado sobre estudos de utilização e consistência de nomenclatura na internet brasileira. Logo, o framework construído apresenta-se, primeiramente, como um guia para a utilização de tais princípios no desenvolvimento de portais universitários. Posteriormente, este trabalho pode se tornar ponto de partida de um estudo maior, utilizando um universo de pesquisa mais amplo.

\section{REFERÊNCIAS}


AGNER, Luiz. Ergodesign e Arquitetura de Informação: Trabalhando com o Usuário. Rio de Janeiro: Quartet, 2006.

APPLETON, B. Patterns and Software: Essential concepts and terminology. CM Crossroads, 2011. Disponível em: <http://www.cmcrossroads.com/ bradapp/docs/patterns-intro.html>. Acesso em 26 fev. 2014.

$\mathrm{BACH}$, Cédric; SCAPIN, Dominique. Ergonomic criteria adapted to human virtual environment interaction. IHM, 2003.

BASTIEN, Christian; SCAPIN, Dominique. Ergonomic criteria for the evaluation of human-computer interfaces. INRIA, Rocquencourt, France, 1993.

CORNELLA, Alfons. Hacia la empresa en red. Barcelona: Ediciones Gestión, 2003.

FAYAD, W. E. et al. TCC Jhony. Uma análise entre frameworks de php, 2006. Disponivel em: <http://www2.unochapeco.edu.br/ jhony/tcc.pdf>. Acesso em 2 fev. 2014.

KRUG, Steve. Não me faça pensar. Rio de Janeiro: Alta Books. 2008.

LOSADA DÍAZ, José Carlos. Prensa e imagen corporativa en la Universidad. Murcia: Fundación Universitaria San Antonio, 2002.

MEMÓRIA, Felipe. Design para a Internet: projetando a experiência perfeita. Rio de Janeiro: Campus/Elsevier, 2005.

MINISTÉRIO DA EDUCAÇÂO. Dados sobre a educação superior são liberados para consulta. Disponível em: <http://www.brasil.gov.br/educacao/2013/10/dados-sobreeducacao-superior-sao-liberados-para-consulta>. Acesso em 7 mar. 2014.

NIELSEN, J. Ten Usability Heuristics. 2005. Disponível em: <http://www.useit.com/papers/heuristic/heuristic_list.html>. Acesso em: 24 fev. 2014.

NIELSEN, Jacob; LORANGER, Hoa. Usabilidade na Web: Projetando Websites com Qualidade. Rio de Janeiro: Campus, 2007.

NIELSEN, Jakob. Projetando Websites. Rio de Janeiro: Elsiever, 2000.

NORMAN, Don. O design do dia-a-dia. São Paulo: Rocco, 2006.

PADOVANI, Stephania; MOURA, Dinara. Navegação para hipermídia: uma abordagem centrada no usuário. Rio de Janeiro: Ciência Moderna, 2008.

PREECE, Jennifer; SHARP, Helen; ROGERS, Yvonne. Design de Interação: Além da Interação Homem-Computador. 3ạ ed. Porto Alegre: Bookman, 2013.

RICHARDSON, Roberto Jarry. Pesquisa social: métodos e técnicas. São Paulo: Atlas, 1989.

SANTAMARIA, Sérgio Ortega; MONTEIRO, Yusef Hassan. Análise e avaliação de sites universitários espanhóis do processo de Bolonha. Perspectivas em Ciência da Informação, v.18, n.4, p.70-92, out./dez. 2013. Disponível em: $<$ http://portaldeperiodicos.eci.ufmg.br/index.php/pci/article/view/1621/1208>.Acesso em 7 mar. 2014. 
SHNEIDERMAN, Ben. Designing the User Interface: Strategies for Effective HumanComputer Interaction, 5th edition. With C. Plaisant. Addison-Wesley. 2010.

SHNEIDERMAN, Ben. O laptop de Leonardo. São Paulo: Nova Fronteira, 2007.

WILLIAMS, Robin; TOLLETT, John. Web design para não-designers. Rio de Janeiro: Editora Ciência Moderna Ltda., 2001. 